\title{
REVIEW \\ Poly(organophosphazene)s and the Sol-gel Technique
}

\author{
Massimo Guglielmi, ${ }^{1 *}$ Giovanna Brusatin, ${ }^{1}$ Giacomo Facchin ${ }^{2}$ and \\ Mario Gleria ${ }^{3 *}$ \\ ${ }^{1}$ Dipartimento di Ingegneria Meccanica, Settore Materiali, Università di Padova, Via Marzolo 9, 35131 \\ Padova, Italy \\ ${ }^{2}$ Centro di Chimica e Tecnologia dei Composti Metallorganici degli Elementi di Transizione del Consiglio \\ Nazionale delle Ricerche, c/o Istituto di Chimica Industriale, Facoltà di Ingegneria dell'Università di \\ Padova, Via Marzolo 9, 35131 Padova, Italy \\ ${ }^{3}$ Istituto di Fotochimica e Radiazioni d'Alta Energia del CNR, Sezione di Legnaro, Via Romea 4, 35020 \\ Legnaro, Padova, Italy
}

We report a survey of the utilization of phosphazene materials in combination with metal alkoxide precursors to form ceramics through the sol-gel technique. Silicon, titanium, zirconium and aluminum three-dimensional oxide networks were exploited for these investigations, while variably functionalized poly[bis (2,2,2-trifluoroethoxy)phosphazene], poly[bis (methoxyethoxyethoxy)phosphazene] and poly [bis(4-hydroxyphenoxy)phosphazene] were used as phosphazene substrates. The resulting new hybrid materials, characterized by SEM, EDAX, DTA, TGA, DSC, DMTA and impedance techniques, showed improved thermal and mechanical stability, and higher ionic conductivity when doped with $\mathrm{Li}^{+}$or $\mathrm{Ag}^{+}$triflates, than those observed for the corresponding original polyphosphazenes. Copyright (C) 1999 John Wiley \& Sons, Ltd.

Keywords: poly(organophosphazene)s; cyclophosphazenes; sol-gel technique; hybrid materials; ionic conductivity; thermo-mechanical characterization

\section{INTRODUCTION}

In the last 20 years there has been a growing interest

* Correspondence to: Massimo Guglielmi, Dipartimento di Ingegneria Meccanica, Settove Materiali, Università di Padova, Via Marzolo 9, 35131 Padova, Italy or Mario Gleria, Institute di Fotochimica e Radiazioni d'Alta Energia del CNR, Sezione di Legnaro, via Romea 4, 35020 Legnaro, Padova, Italy. in the preparation of organosilicon/phosphazene mixed macromolecules, due to the very good elastomeric properties of these two classes of compounds, the large variety of poly(organophosphazene) structures that can be designed and synthesized, and the very interesting industrial applications of these two types of polymeric materials. ${ }^{1-6}$

In this work, which has been highlighted by a number of reviews, ${ }^{7-10}$ it was stressed that several strategies exist to prepare new silicon/phosphazene hybrid materials, mainly based on the use of:

(1) substitution reactions of $\left(\mathrm{NPCl}_{2}\right)_{n}$ or $\left(\mathrm{NPF}_{2}\right)_{n}$ halogens with silanolates, ${ }^{10}$ amino-organosilanes ${ }^{11}$ or organosilyl Grignard or lithium reagents; ${ }^{12}$

(2) functionalizations of previously synthesized phosphazene macromolecules (POPs) using, for instance, hydrosilylation processes ${ }^{13}$ or deprotonated phosphazene reactions with organosilicon halides; ${ }^{14}$

(3) surface modification of polyphosphazene films with siloxanes, ${ }^{15}$

(4) formation of blends ${ }^{10,16}$ or of interpenetrating polymer networks ${ }^{10}$ between these two types of polymeric materials;

(5) grafting processes of polysiloxanes onto polyphosphazene matrices. ${ }^{17-19}$

All these investigations led to the preparation of a remarkable number of polyphosphazenes functionalized with both low-molecular-weight linear or cyclic silicon-containing molecules, and to the synthesis of high-molecular-weight phosphazene/ siloxane mixed materials.

Among the possible ways in which hybrid 
silicone-containing polyphosphazene substrates can be obtained, particular attention should be paid to the sol-gel technique, ${ }^{20}$ a process that allows the incorporation of a variety of phosphazene macromolecules into three dimensional siloxane networks. According to this process, a silicon or a metal alkoxide precursor is hydrolyzed under acid or alkaline conditions to form species containing free hydroxylic groups that are able to condense to form an insoluble crosslinked network.

In the case of tetraethoxysilane $\left[\mathrm{Si}(\mathrm{OEt})_{4}\right.$, TEOS], the overall reaction sequence can be written as Equations [1-3].

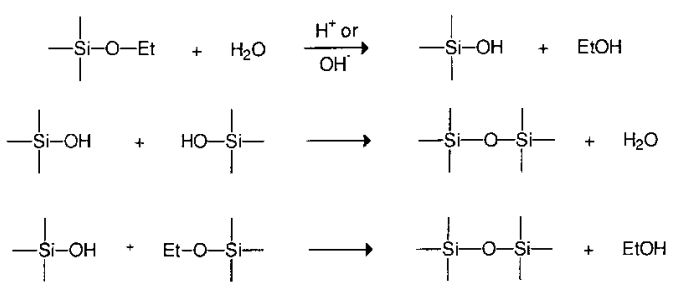

When additional products, other than alkoxide precursors and phosphazene substrates, are added to this reaction system $\left(\mathrm{Li}^{+}\right.$or $\mathrm{Ag}^{+}$salts, for instance), these species will be embodied in the silicon glass to form a new, hybrid material that may exhibit novel and interesting properties with respect to those initially shown by the pristine substrates.

In the field of poly(organophosphazene)s, this approach to the preparation of hybrid materials was explored by Ferrar, ${ }^{21-28}$ by Allcock ${ }^{10}$ and by our group $^{29-38}$ to synthesize new ceramics exhibiting ionic conductivity ${ }^{21-28,33,36,37}$ and optical absorption in the visible range of the spectrum, ${ }^{31}$ together with improved thermal and mechanical resistance $21,22,25,27-30,32,36$, film- and fiber-forming capability, ${ }^{21,22,25,27,28}$ high flexibility of protective coatings, ${ }^{36}$ etc.

Here we critically highlight the work done on the utilization of the sol-gel technique in the case of poly(organophosphazene)s and discuss the chemico-physical characteristics of the resulting hybrid materials.

\section{DISCUSSION}

\section{Poly[bis(methoxy-ethoxy- ethoxy)phosphazenel/metal oxide hybrid materials}

One of the first phosphazene polymers exploited for the formation of hybrid materials in combination with different types of metal alkoxides was poly[bis(methoxy-ethoxy-ethoxy)phosphazene], MEEP. The synthesis of this polymer, first reported by Allcock in $1984,{ }^{39}$ is achieved by reacting polydichlorophosphazene $\mathrm{e}^{40-42}$ with di(ethylene glycol) monomethylether to form a polymer, $\mathbf{1}$, in which two short-chain ethylene oxide units are attached to the phosphorus atoms of the polyphosphazene skeleton.

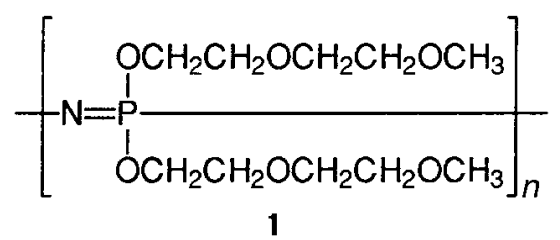

The importance of this substrate as a watersoluble polymer, ${ }^{43,44}$ as a biologically interesting macromolecule, ${ }^{45,46}$ as a phase-transfer catalyst ${ }^{47}$ and as an ionic conductor when doped with lithium or silver triflates 39,48 was recognized almost immediately, and was attributed to some advantageous properties of the polymer, such as the superior hydrophilicity of the ethylene oxide substituents (which favors the biocompatibility of this polymer, ${ }^{46,49,50}$ the high coordinating ability of the etheric side groups for inorganic salts, ${ }^{51-53}$ the very low $T_{\mathrm{g}}\left(-75^{\circ} \mathrm{C}^{54}\right)$ and its amorphous structure. $^{22,25^{\mathrm{g}}}$

MEEP polymer, therefore, could be an ideal candidate for biomedical investigations, ${ }^{55}$ reaction catalysis $^{47}$ and the construction of light batteries. ${ }^{56}$

This macromolecule, however, suffers for an intrinsic drawback, i.e. the very low dimensional stability, ${ }^{57}$ that prevents its extensive use in battery construction technology. At ambient temperature, in fact, MEEP is in the visco-elastic flow regime, ${ }^{22,25}$ and can therefore flow like a viscous liquid without retaining its form when subjected to an external force. For these reasons the mechanical properties of MEEP need to be improved in order to facilitate its practical utilization; this aim was achieved in the past by chemical, ${ }^{58}$ photochemi$\mathrm{cal}^{59}$ or $\gamma$-radiolytic ${ }^{49,60}$ reticulation of the polymer, and by blending it with crystalline poly(ethylene oxide). ${ }^{61,62}$

However, a novel route was recently proposed to improve the mechanical properties of MEEP, based on the preparation of composite materials showing controlled morphology and physical properties. This alternative possibility uses the sol-gel technique, by incorporating MEEP in different metal oxide three dimensional net- 


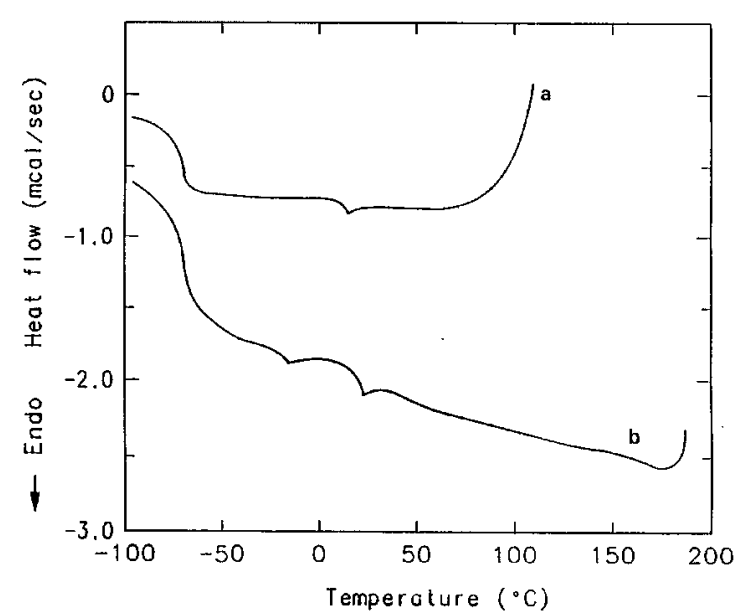

Figure 1 DSC thermograms of (a) MEEP homopolymer and (b) MEEP/TEOS 50:50 composite. The $\mathrm{T}_{\mathrm{g}}$ is $-75^{\circ} \mathrm{C}$ for both the homopolymer and the polymer in the composite. Reproduced with permission from reference 25. Copyright 1992, American Chemical Society.

works. ${ }^{21,22,25,27,28,33,36,37}$ Accordingly, several different new composites have been prepared in this way: they are described briefly below.

\section{$\mathrm{MEEP} / \mathrm{SiO}_{2}$ composites}

The preparation of these new phosphazene/metal oxide hybrid materials was achieved by dissolving MEEP in a 1:1 THF/ethanol mixture, adding small amounts of tetraethoxysilane (TEOS) oxide precursor, water reagent and catalytic amounts of hydrochloric acid, stirring the solution for some time at $60^{\circ} \mathrm{C}$, pouring the reaction mixture in a Teflon ${ }^{\circledR}$ mold, and eventually allowing the solvent to evaporate at room temperature for a few days. $^{22,23,25}$

The resulting $\mathrm{MEEP} / \mathrm{SiO}_{2}$ composite material was successively characterized by differential scanning calorimetry (DSC), thermogravimetric analysis (TGA), and dynamico-mechanical (DMTA) tests.

DSC analysis showed (Fig. 1) that:

(1) the glass transition temperature $\left(T_{\mathrm{g}}\right)$ of both $\mathrm{MEEP}$ and $\mathrm{MEEP} / \mathrm{SiO}_{2}$ composites is close to $-75^{\circ} \mathrm{C}$, to indicate that the interactions between the three-dimensional silica network and the phosphazene substrate are quite feeble, and are not able, in any case, to influence the polyphosphazene skeleton mobility;

(2) both substrates show a small endothermic

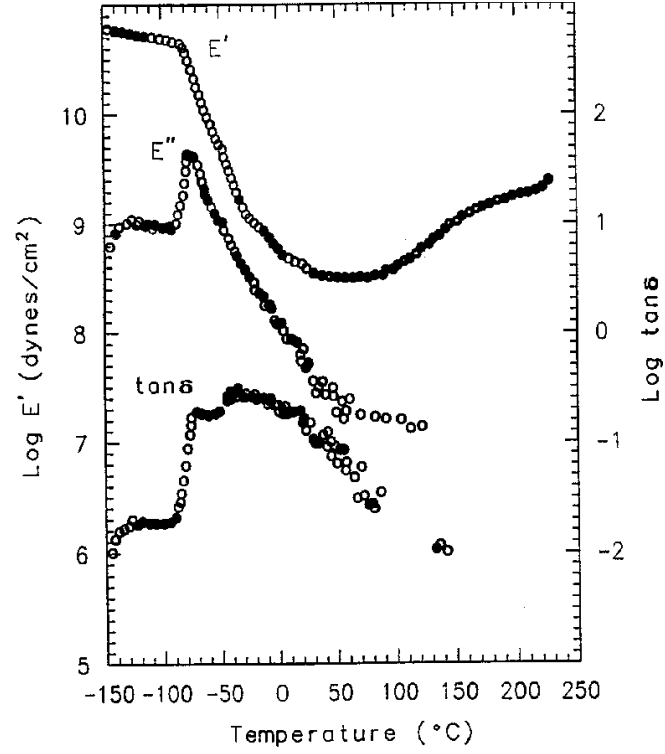

Figure 2 Dynamic mechanical spectrum of the acid-catalyzed MEEP/TEOS 50:50 composite cured at ambient temperature. Reproduced with permission from reference 25 . Copyright 1992, American Chemical Society.

peak in the thermograms, located at $20-30{ }^{\circ} \mathrm{C}$ and tentatively assigned to the melting of some crystallites;

(3) an exothermal transition for the MEEP homopolymer (Fig. 1) is located above $100{ }^{\circ} \mathrm{C}$; it is attributed to the onset of polymer degradation phenomena. The same transition is also present in the DSC thermogram of the $\mathrm{MEEP} / \mathrm{SiO}_{2}$ hybrid, but located at $200{ }^{\circ} \mathrm{C}$, to suggest that a strong thermal stabilization effect occurs when the phosphazene polymer is blended with the silicon oxide.

Furthermore, thermogravimetric experiments showed that the MEEP homopolymer and the $\mathrm{MEEP} / \mathrm{SiO}_{2}$ composite have similar behavior upon heating, with an initial weight loss at $240{ }^{\circ} \mathrm{C}$ then a successive enhanced loss starting at $306{ }^{\circ} \mathrm{C}$.

Quite interesting results are found during DMTA measurements for a free-standing film of MEEP/ $\mathrm{SiO}_{2}$ composite materials. According to Fig. 2, where the storage $\left(E^{\prime}\right)$ and loss $\left(E^{\prime \prime}\right)$ modulus and $\tan \delta$ are plotted against temperature, $E^{\prime}$ decreases with an increase in temperature up to $30^{\circ} \mathrm{C}$ after this point it starts again to increase due to additional $\mathrm{SiO}_{2}$ reticulation processes.

From the analysis of these data it appears quite clear that the mechanical properties of $\mathrm{MEEP} / \mathrm{SiO}_{2}$ 


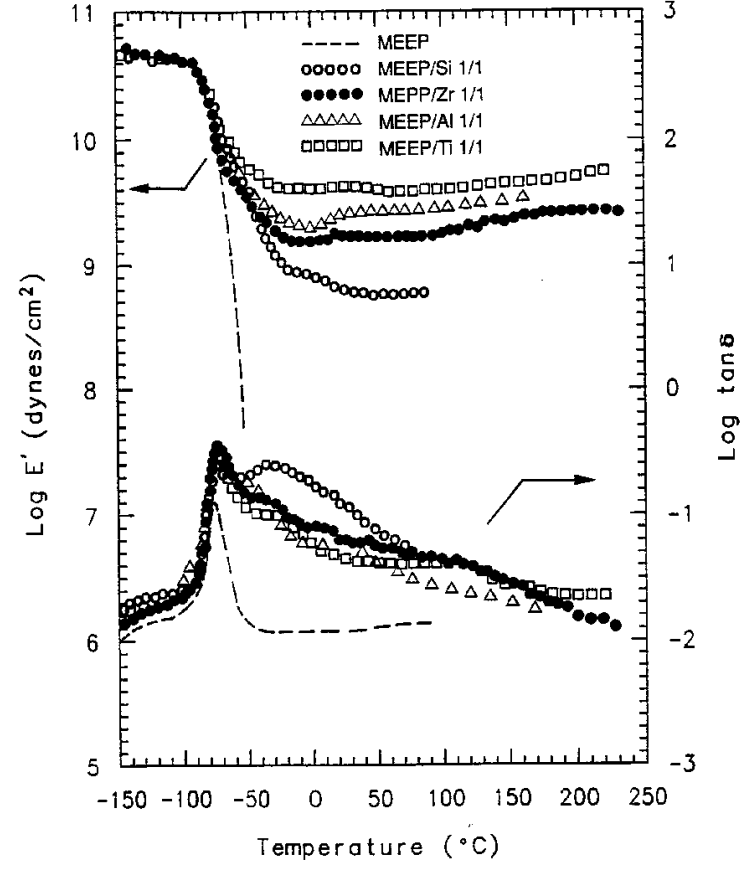

Figure 3 Dynamic mechanical spectra of MEEP and MEEP composites. Reproduced with permission from reference 28 . Copyright 1994, American Chemical Society.

composites (assigned to the interactions between the three-dimensional $\mathrm{SiO}_{2}$ network and the etheric substituent of the phosphazene material) are significantly superior to those of the MEEP homopolymer, and that the thermal stability of MEEP is considerably enhanced by blending this polymer with the silicon oxide network.

\section{$\mathrm{MEEP} / \mathrm{TiO}_{2}, \mathrm{MEEP} / \mathrm{ZrO}_{2}$ and $\mathrm{MEEP} / \mathrm{Al}_{2} \mathrm{O}_{3}$ hybrids}

The synthetic procedures described above for the preparation of $\mathrm{MEEP} / \mathrm{SiO}_{2}$ composite materials were successively extended to other, more reactive, metal oxide precursors (titanium, zirconium and aluminum) to obtain new hybrids formed by $\mathrm{MEEP} / \mathrm{TiO}_{2}, \mathrm{MEEP} / \mathrm{ZrO}_{2}$ and $\mathrm{MEEP} / \mathrm{Al}_{2} \mathrm{O}_{3}$ networks. $^{27,28}$

Dynamico-mechanical (DMTA) characterizations of these materials (Fig. 3) showed that the storage modulus $E^{\prime}$ for all the measured composites decreases with an increase in temperature in the region of $T_{\mathrm{g}}\left(-75^{\circ} \mathrm{C}\right)$ until $-20^{\circ} \mathrm{C}$ is reached, and then it starts to increase again very smoothly. No further condensation reactions could be found for $\mathrm{TiO}_{2}, \mathrm{ZrO}_{2}$ or $\mathrm{Al}_{2} \mathrm{O}_{3}$ networks, which should lead

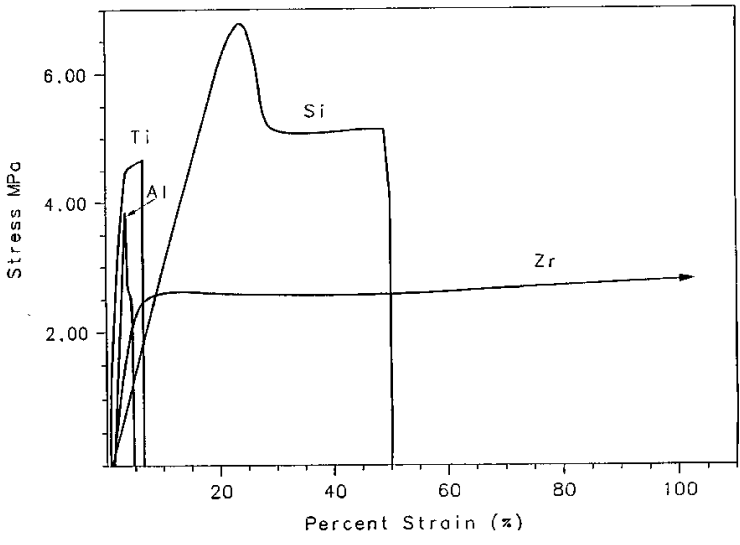

Figure 4 Stress-strain curves of MEEP composites (1:1). Reproduced with permission from reference 28. Copyright 1994, American Chemical Society.

to the strong enhancement of $E^{\prime}$ previously observed for the $\mathrm{MEEP} / \mathrm{SiO}_{2}$ composites. ${ }^{2,25}$ These facts could be accounted for on the basis of the considerably higher reactivity of these metal oxides, leading, to the network formation process more rapidly than in the case of $\mathrm{SiO}_{2}$ systems.

Moreover, the stress-strain curves (Fig. 4) for 1:1 (w/w) MEEP/metal oxide composites proved to be characteristics of a ductile glassy polymer, ${ }^{27,28}$ appeared to be strongly influenced by the nature of the metal oxides, and indicated convincingly that these metal oxides have a significant effect in reinforcing MEEP. ${ }^{27,28}$

Quite interestingly, the addition of up to $17 \%$ (w/w) of potassium triflate to the MEEP/alkoxide THF/ethanol solution does not bring about remarkable differences in the process of formation of the hybrid materials. The presence of this salt, however, is able to induce ionic conductive phenomena in the composites similar to those previously observed for the MEEP homopolymer system, 39,63 with conductivity values in the region of $10^{-5}$ $\omega^{-1} \mathrm{~cm}^{-1} \cdot 27,28$

\section{$\mathrm{MEEP} / \mathrm{ZrO}_{2}$ and $\mathrm{MEEP} / \mathrm{TiO}_{2}$ fibers}

Fibers formed by MEEP polymer blended with metal oxides $\left(\mathrm{TiO}_{2}\right.$ and $\left.\mathrm{ZrO}_{2}\right)$ in a sol-gel process, optionally containing inorganic salts to favor the onset of conductive phenomena, were reported by Ferrar and co-workers. ${ }^{21,24,26}$ These fibers were prepared by dissolving the phosphazene polymer in ethanol and adding the appropriate inorganic alkoxide precursor (together with the inorganic salt, if necessary), the water reagent and the acid 
catalyst, by extruding the solution into fibers and eventually curing them under controlled conditions, at room temperature or under gentle heating.

This simple process leads to the formation of blends in which the metal alkoxide and the phosphazene macromolecule are merely blended, without the formation of any covalent crosslinks between these two components.

\section{Hydroxylated MEEP/Silica, MEEPOH/SiO composites}

In spite of the remarkable results obtained in the formation of $\mathrm{MEEP} / \mathrm{metal}$ oxide hybrid materials through the sol-gel technique $21,22,25,27,28$ reported above, the substrates prepared suffer for a major disadvantage, related principally to the lack of chemical interactions between the MEEP polymer and the metal oxides.

Our group was able to overcome this problem by considering a novel macromolecule substituted with ethylene oxide residues, but containing a high proportion of free hydroxylic functionalities. i.e. poly[bis(methoxy-ethoxy-ethoxy) ${ }_{1,2}$ (hydroxyethoxy-ethoxy) 0.8 phosphazene] (MEEPOH,2).

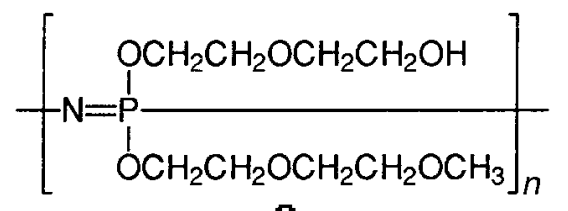$$
2
$$

This polymer has been synthesized by De Jaeger $^{64,65}$ by treating MEEP with trimethylsilyl iodide $^{66}$ to remove the protective methyl residue at the end of the ethylene oxide chain and set free the corresponding hydroxylic groups.

This macromolecule shows physical characteristics similar to those of the pristine MEEP, ${ }^{64,65}$ i.e. amorphous structure, flowing capability at room temperature and low $T_{\mathrm{g}}\left(-70.9^{\circ} \mathrm{C}\right)$, but it is able to react with the hydrolyzed TEOS when dissolved in ethanol solutions in the presence of water reagent and hydrochloric acid catalyst (Eqn 4)

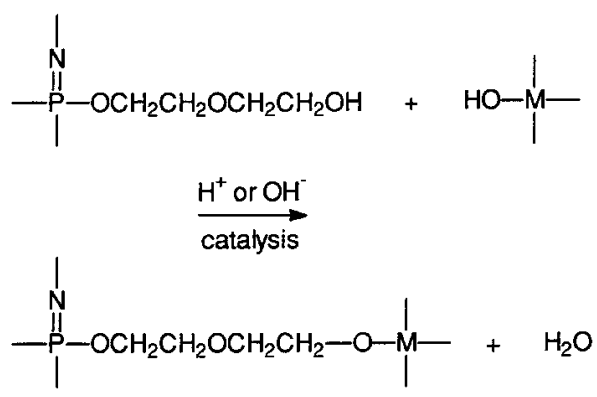

Copyright (C) 1999 John Wiley \& Sons, Ltd.

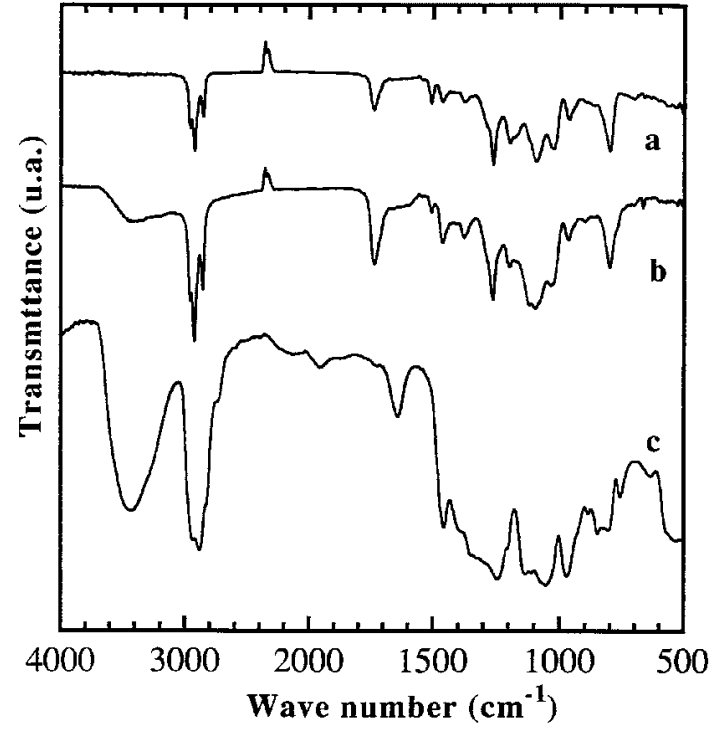

Figure 5 FTIR spectra of: (a) polymer extracted by acetone from hybrid powder (MEEPOH/SiO $\left.\mathrm{S}_{2}=1: 8\right)$; (b) polymer extracted by acetone from hybrid powder after hydrolytic treatment; (c) pure MEEPOH.

It is important to stress that the addition of inorganic salts $\left(\mathrm{Li}^{+}\right.$or $\mathrm{Ag}^{+}$triflates) to the reaction mixture does not alter the process of formation of the glassy substrates.

The resulting MEEPOH/metal alkoxide composite is a completely homogeneous and transparent material, as proved both by scanning electron microscopy (SEM) and energy-dispersive X-Ray analysis (EDAX) tests, where the hydroxylated phosphazene polymer is chemically bonded to the silicon oxide three-dimensional network. 33,36,37

This last fact was checked by solvent extraction tests carried out on both the $\mathrm{MEEPOH} / \mathrm{SiO}_{2}$ composite and on physical blends of the same compounds (Fig. 5) and by DSC characterization experiments (Fig. 6). When the $\mathrm{MEEPOH} / \mathrm{SiO}_{2}$ hybrid was treated with acetone (i.e. a solvent in which MEEPOH is very soluble) only negligible amounts of polymer could be extracted (Fig. 5, curve $\mathrm{b}$ ), in contrast to the substration when $\mathrm{MEEPOH} / \mathrm{SiO}_{2}$ physical blends (Fig. 5, curve c) were used. Furthermore, a DSC thermogram of the $\mathrm{MEEPOH} / \mathrm{SiO}_{2}$ composite (Fig. 6, curve b) shows that no glass transition temperature $T_{\mathrm{g}}$ of the pristine $\mathrm{MEEPOH}$ (originally located at $-70.9^{\circ} \mathrm{C}$ : see Fig. 6, curve a) is observable, to support the formation of a homogeneous material.

This new $\mathrm{MEEPOH} / \mathrm{SiO}_{2}$ hybrid substrate 


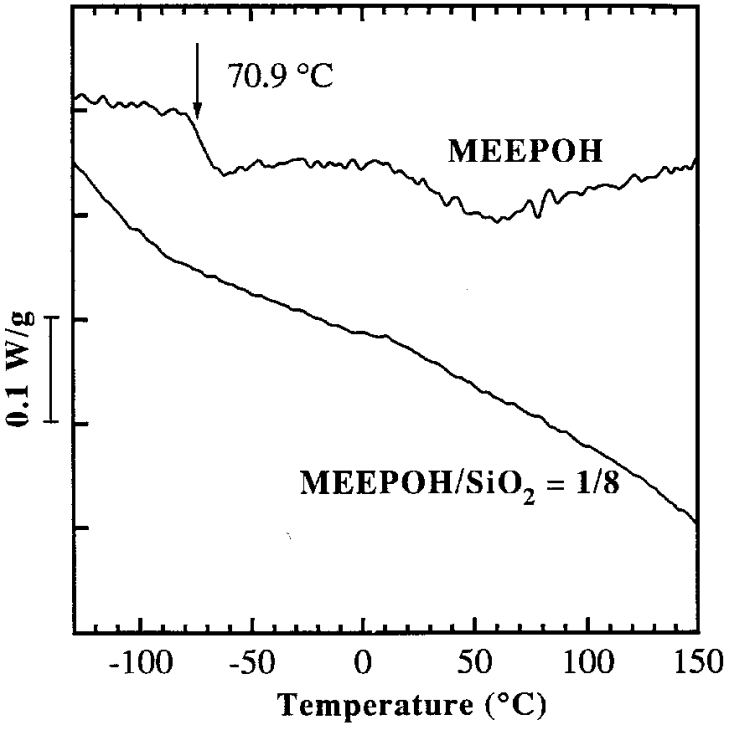

Figure 6 DSC analyses. In the hybrid, $\mathrm{MEEPOH} / \mathrm{SiO}_{2}=1: 8$.

proved to be a very interesting composite that showed a high ionic conductivity when doped with lithium triflate. ${ }^{33,37}$

The conductive behavior of this material is demonstrated in Fig. 7, where the Nyquist impedance plot is reported for a $\mathrm{MEEPOH} / \mathrm{SiO}_{2}$ hybrid sample treated as described in the Figure caption.

For the lithium-free samples treated at $60{ }^{\circ} \mathrm{C}$, the ionic conductivity is close to $3 \times 10^{-6} \omega^{-1} \mathrm{~cm}^{-1}$, and about 10 times higher for those containing lithium triflate. The high conductivity of the former is probably the result of $\mathrm{H}^{+}$transport. Owing to this large background conductivity, the addition of

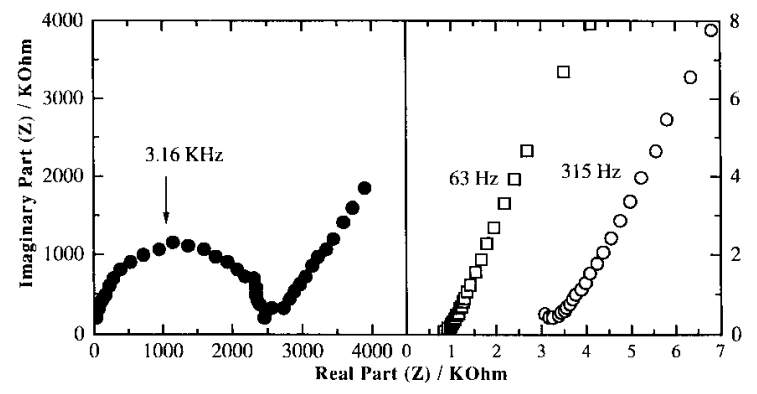

Figure 7 Impedance plots of $\mathrm{MEEPOH} / \mathrm{SiO}_{2}$ hybrids: treated at $120^{\circ} \mathrm{C}, 142 \mu \mathrm{m}$ thick and without lithium triflate added; and treated at $60^{\circ} \mathrm{C}(\square)$ and $120^{\circ} \mathrm{C}(\bigcirc), 105 \mu \mathrm{m}$ thick and with $1 \mathrm{M}$ lithium triflate added.

Copyright (C) 1999 John Wiley \& Sons, Ltd.
$\mathrm{LiCF}_{3} \mathrm{SO}_{3}$ increases the sample conductivity by only one order of magnitude. Differences between Li-free and Li-containing samples become much sharper for samples submitted to a thermal treatment at $120^{\circ} \mathrm{C}$, which is likely to remove water from the sample and induce a more complete reaction between the inorganic and organic components of the hybrid material, with the formation of a large number of $\mathrm{Si}-\mathrm{O}-\mathrm{C}$ bonds. With this treatment the conductivity of the lithium-free samples drops by about two orders of magnitude, while that of the lithium-containing materials decreases by a factor of only four.

\section{Poly[bis(4- hydroxyphenoxy)phosphazene]/ metal oxide composites}

Poly[bis(4-hydroxyphenoxy)phosphazene] (PO$\mathrm{POH}, 3)$ is another intriguing polymer that occupies a relevant position in modern phosphazene research.

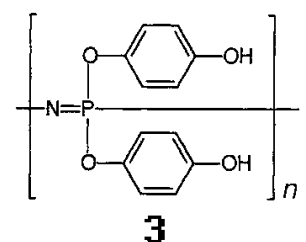

First synthesized in our group ${ }^{67}$ starting from poly[bis(4-methoxyphenoxy)phosphazene] by reaction with boron tribromide, ${ }^{66}$ this polymer was then used for a number of functionalization reactions made possible by the high reactivity of the free hydroxylic groups present in the para position of the side-chain phenoxy substituents.

Thus the reaction of $\mathrm{POPOH}$ with acetic anhydride $^{67}$ led to the synthesis of poly[bis(4acetyloxy-phenoxy)phosphazene], a polymer potentially useful in photoresist technology; ${ }^{68}$ POPOH, moreover, was reacted with carboxylic acids, acyl chlorides and $\alpha$-bromomethylene derivatives containing carbon-carbon double bonds to introduce chemical unsaturations into the phosphazene substrates. ${ }^{69}$ The phosphazene macromolecules containing ethylene groups that were obtained were successively peroxidized by the action of $m$-chloroperbenzoic acid to form new polyphosphazenes functionalized with a controlled number of epoxy units. Both of these last two series of POPs are potentially useful materials for crosslinking generation, either by thermal and/or photochemical opening of the double bond system in 
these polymers, or by acid or alkaline polymerization of the oxirane ring. ${ }^{70} \mathrm{~A}$ third series of functionalization reactions of $\mathrm{POPOH}$ could be achieved by treating the free hydroxylic functions with BOC (di-t-butyl-dicarbonate) reagent, ${ }^{71,72}$ with cinnamoyl chloride ${ }^{73}$ or chalcone groups. ${ }^{74}$ The potential applicability of these new BOCcontaining phosphazene macromolecules in photoresist technology is at present under consideration.

The presence of free hydroxylic functions in $\mathrm{POPOH}$, therefore, and the high reactivity of these groups make $\mathrm{POPOH}$ an ideal candidate for exploitation in sol-gel technology for the preparation of new hybrid materials containing the polyphosphazene structure.

According to the principle, now generally accepted in phosphazene research, that cyclophosphazenes are excellent low-molecular-weight model compounds for the corresponding high polymers, ${ }^{9,75}$ we started our research in the field of sol-gel hybrid materials containing phosphazene substrates by first investigating cyclophosphazene derivatives, only later expanding our study to phosphazene macromolecular systems.

Pentakis(phenoxy)mono(4-

hydroxyphenoxy)cyclophosphazene (TOH1) and hexakis(4-hydroxyphenoxy)cyclophosphazene (TOH6)/silicon oxide hybrids

The hybrid materials based on the cyclophosphazenes TOH1 (4) and TOH6 ${ }^{67}(\mathbf{5})$ were obtained ${ }^{29,30}$

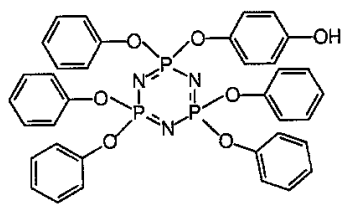

$4: \mathrm{TOH} 1$

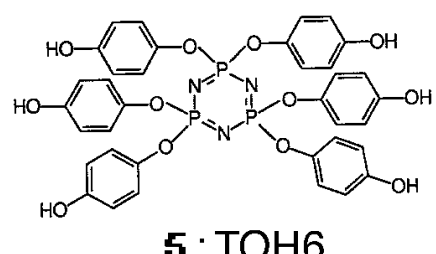

by treating these trimers with:

(a) water-containing ethanol solutions of TEOS, pre-hydrolyzed under acidic conditions for 1 , 3 on $12 \mathrm{~h}$ (solutions S1, S3 and S12, respectively) at reflux temperature;

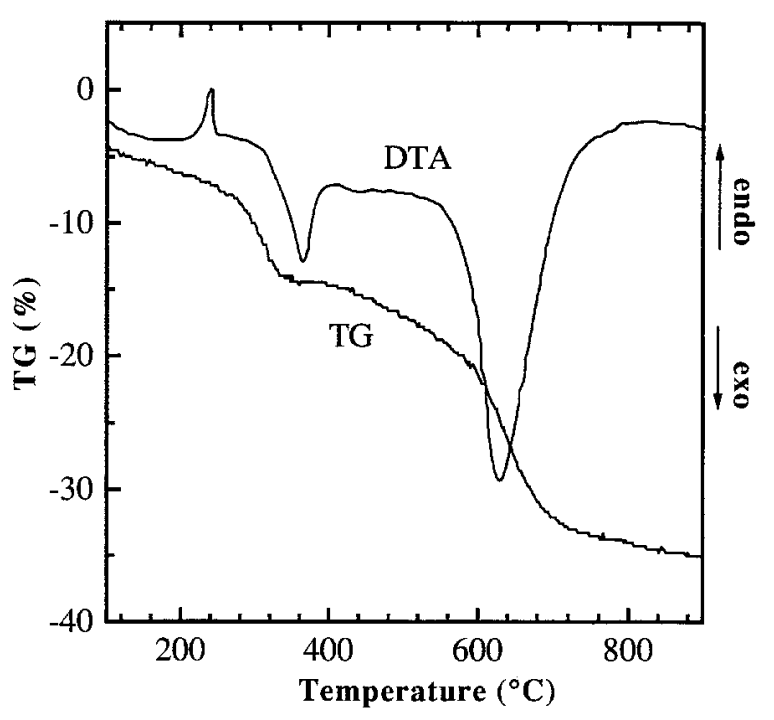

Figure 8 DTA and TGA analyses for hybrid containing TOH6 and TEOS (S12); phosphazene OH equivalents/TEOS molar ratio $=1: 2.5$.

(b) water-free, acetylacetone (1:1)-stabilized ethanol solutions of $\mathrm{Ti}(\mathrm{OBu})_{4}$ or $\mathrm{Zr}(\mathrm{OBu})_{4}$.

Under the above-mentioned conditions TOH1 reacts in an incomplete way with $\mathrm{S} 1$ and $\mathrm{S} 3$ solutions of TEOS leaving a considerable amount of the trimer unreacted in the final composite material; this could be proved both by an extraction test on the final composite with acetone (vide infra) and by differential thermal analysis (DTA), which demonstrated the presence of an endothermic peak at $106{ }^{\circ} \mathrm{C}$ attributed to the melting of the residual trimer not incorporated in the silicon oxide network. 29,30

More complete reaction patterns could be obtained $^{30}$ by reacting TOH6 with S1, S3 and S12 TEOS solutions, in the sense that its melting peak at $240{ }^{\circ} \mathrm{C}$ is present in the DTA curve for $\mathrm{S} 1$ and $\mathrm{S} 12$ solutions (Fig. 8), but it has almost disappeared when S3 conditions are considered.

In contrast, the reactivity of both trimers is almost instantaneous when $\mathrm{Ti}$ and $\mathrm{Zr}$ hydrolyzed butoxide precursors are used. ${ }^{30}$ In fact, precipitation was always observed for the TOH6 in combination with $\mathrm{Ti}(\mathrm{OBu})_{4}$ or $\mathrm{Zr}(\mathrm{OBu})_{4}$ in all the experimental conditions tested. The stabilization of these alkoxides with acetylacetonate avoided the formation of precipitates only for the TOH6/ $\mathrm{Ti}(\mathrm{OBu})_{4}$ system, while for the monohydroxylated cyclophosphazene TOH1 clear sols could be 
obtained for both $\operatorname{Ti}(\mathrm{OBu})_{4}$ and $\mathrm{Zr}(\mathrm{OBu})_{4}$ metal oxide precursors.

These results indicated that the presence of one or six free hydroxylic groups in the cyclophosphazenes is able to produce the complete reaction of the metal alkoxide precursors only when $\mathrm{Ti}(\mathrm{OBu})_{4}$ or $\mathrm{Zr}(\mathrm{OBu})_{4}$ is used. TEOS appears to be less reactive than titanium or zirconium butoxide derivatives (the reactivity sequence is as follows: $\left.\mathrm{Si}(\mathrm{OEt})_{4}<\mathrm{Ti}(\mathrm{OBu})_{4}<\mathrm{Zr}(\mathrm{OBu})_{4}\right)$ and always allows a certain percentage of hydroxylated trimer to remain unreacted in the composite system, except when the TOH6 cyclophosphazene dissolved in S3 solutions is considered.

\section{$\mathrm{POPOH} / \mathrm{SiO}_{2}$ hybrid materials}

The research on the composites involving the use of $\mathrm{POPOH}$ and alkoxide precursors under acid conditions led to the preparation of new hybrids in the form of bulky materials, flexible coatings and fibers, depending on the experimental conditions adopted. ${ }^{36}$

Several points have been explored in order to optimize the synthesis of these substrates.

The first problem was basically related with the type of metal alkoxide precursor to be used to prepare phosphazene-based ceramics, i.e. TEOS, $\mathrm{Ti}(\mathrm{OBu})_{4}$ or $\mathrm{Zr}(\mathrm{OBu})_{4}$. Experimental results in this field provided evidence that $\mathrm{Ti}(\mathrm{OBu})_{4}$ and $\mathrm{Zr}(\mathrm{O}$ $\mathrm{Bu})_{4}$ reacted so fast with the phosphazene macromolecule that it was necessary to diminish the alkoxide reactivity both by complexing them 1:1 with acetylacetonate and by avoiding the introduction of water in the reaction mixture. In spite of these measures, precipitation was always observed during the reaction of $\mathrm{POPOH}$ with titanium or zirconium butoxide species. ${ }^{30}$

The experiments were therefore continued with TEOS alone, as this precursor proved to be a suitable substrate to form new phosphazene-based hybrid materials.

A second factor that could play an important role in the formation of $\mathrm{POPOH} / \mathrm{SiO}_{2}$ composites was the phosphazene polymer itself. ${ }^{32}$ Experimental observations indicated that $\mathrm{POPOH}$ is a quite unstable macromolecule, very susceptible to air oxidation which induces the yellowing of the polymer and its insolubilization. IR analyses of these processes revealed the possible formation of quinone species from the original hydroxyphenol substituent of $\mathrm{POPOH}$ that led to the formation of $\mathrm{P}-\mathrm{OH}$ units; the condensation of these last species to form $\mathrm{P}-\mathrm{O}-\mathrm{P}$ units is thought to be responsible for the final crosslinking of the polymer. As a

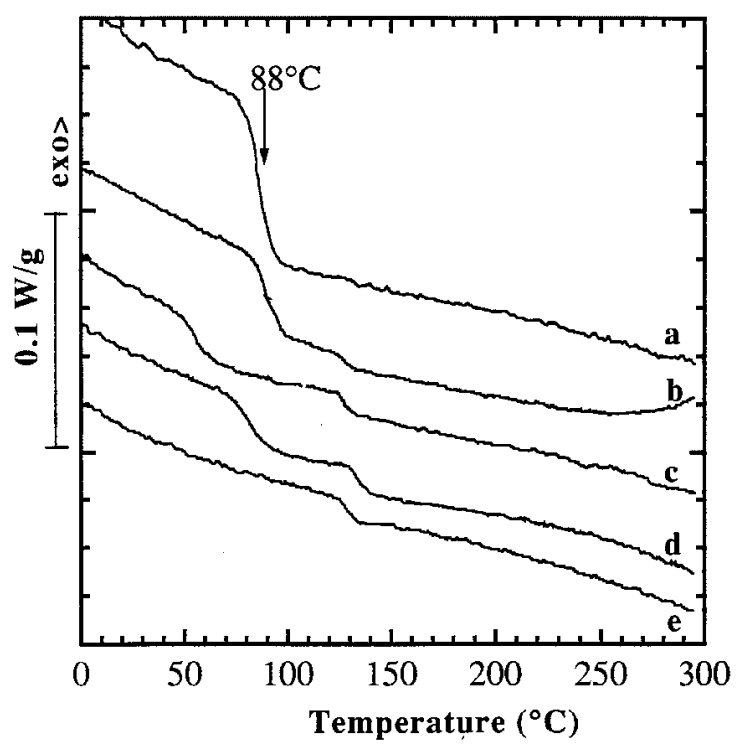

Figure 9 DSC analyses of: (a) pure POPOH; (b) a mechanical mixture of POPOH and silica; (c) a hybrid obtained with oxidized POPOH and silica; (d) an inhomogeneous hybrid obtained with an insufficient reaction time; (e) a homogeneous and transparent hybrid with POPOH and silica.

consequence of these findings, the $\mathrm{POPOH}$ used for the formation of hybrid materials through the sol-gel technique was always prepared just before use, or a macromolecule stored under vacuum conditions in order to minimize the oxidative phenomena.

Taking into account the precautions described above, the reaction of TEOS with ethanol solutions of $\mathrm{POPOH}$, in the presence of water reagent and of $\mathrm{HCl}$ as a catalyst, was attempted by first pre-hydrolyzing TEOS under strictly controlled conditions, in order to check when the maximum concentration of $\mathrm{Si}-\mathrm{OH}$ groups was present in the reaction mixture. This had the aim of ensuring the highest efficiency of the condensation process between $\mathrm{POPOH}$ and the pre-hydrolyzed TEOS.

Ethanol solutions of TEOS, therefore, were treated with water and hydrochloric acid in the pre-hydrolysis step for 3, 6, 9 or $12 \mathrm{~h}$, and $\mathrm{POPOH}$ was added to each of these reaction mixtures. The reaction between $\mathrm{POPOH}$ and the $\mathrm{Si}-\mathrm{OH}$ groups did occur in all these experimental conditions, the solution pre-hydrolyzed for $6 \mathrm{~h}$ showing the best reactivity, but the new hybrids obtained were opaque materials, sometimes presenting relevant phase separation phenomena. ${ }^{32}$

Appl. Organometal. Chem. 13, 339-351 (1999) 
In an attempt to improve this experimental procedure an ethanol solution of freshly prepared POPOH was simultaneously treated with TEOS, reagent water and hydrochloric acid for $6 \mathrm{~h}$ under reflux conditions, in an inert atmosphere, while stirring. The resulting mixture was aged at room temperature for $24 \mathrm{~h}$ in order to allow the condensation process to take place and the phosphazene-based hybrids to be formed. ${ }^{32}$ The substrates prepared in this way were transparent bulk materials, showing no phase separation (by SEM and EDAX analyses), extracted with great difficulty with acetone solvent (vide infra), showing a DSC profile where no $T_{\mathrm{g}}$ of the original POPOH was present at $88^{\circ} \mathrm{C}$ (Fig. 9), and showing a considerably high thermal stability (up to $\left.500{ }^{\circ} \mathrm{C}\right) .^{32}$

The properties of these $\mathrm{POPOH} /$ silica hybrid films, with different TEOS/POPOH molar ratios, were also investigated by indentation tests and after $\mathrm{C}$ or $\mathrm{Au}$ irradiation. ${ }^{35,38}$ It was found that the hardness and the elastic modulus of the phosphazene-based hybrid materials increased with an increase in silica content, also if not proportionally to it. FTIR, ion-beam techniques and optical spectroscopy were used to determine the structure and composition of the irradiated films. During irradiation all parts of the polymeric chains were progressively destroyed. This led to the destruction of the bonds with silica, which formed isolated clusters, and to a higher final hardness of the structure.

\section{Poly[bis $(2,2,2-$ trifluoroethoxy)phosphazenel/metal alkoxide composites}

Poly[bis(2,2,2-trifluoroethoxy)phosphazene]

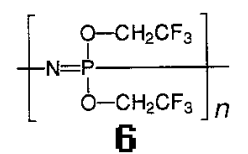

(PTFEP, 6) is one of the most important macromolecules ever synthesized and investigated in the polyphosphazene domain. ${ }^{5}$ This polymer was synthesized starting from polydichlorophosphazene and 2,2,2-trifluoroethoxide, ${ }^{41}$ sometimes in the presence of phase-transfer catalysts ${ }^{76,77}$.

The resulting PTFEP is a film-forming polymer, ${ }^{78}$ showing microcrystallinity, ${ }^{79}$ high thermal stability, ${ }^{80}$ good mechanical properties, ${ }^{81}$ selfextinguishability and flame retardance, ${ }^{82}$ great hydrolytic stability, ${ }^{6}$ acid, ${ }^{5}$ alkaline ${ }^{5}$ and aromatic solvent resistance ${ }^{83}$ and remarkable biological inertness. ${ }^{55,84}$

\section{Hydroxylated poly[bis $(2,2,2-$}

trifluoroethoxy)phosphazene $] / \mathrm{SiO}_{2}$ composites The use the fluorinated polymer $\mathbf{6}$ in the sol-gel technique to form composites was first attempted by Ferrar and co-workers, ${ }^{22,25}$ who exploited a modified form of PTFEP (PTFEPOH, 7) ${ }^{85}$ which

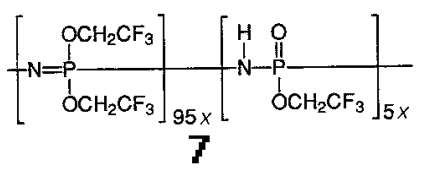

incorporated about $5 \%$ of hydrolyzed phosphazene units. This makes PTFEPOH compatible with the TEOS ethanol solutions and allows the preparation of fluorophosphazene-based hybrid materials. ${ }^{25}$ Such products could be prepared by dissolving $\mathrm{PTFEPOH}$ in ethanol, treating this solution with hydrolysis water and $\mathrm{NH}_{4} \mathrm{OH}$ (alkaline catalysis), and heating the resulting solution at $60^{\circ} \mathrm{C}$ for $30 \mathrm{~min}$. The reaction mixture was then poured into

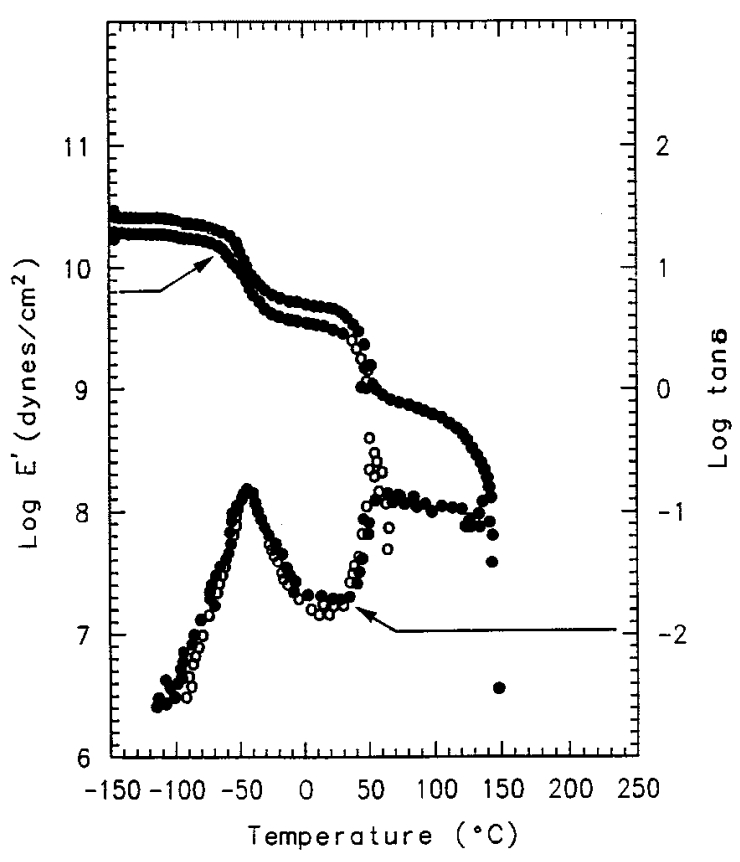

Figure 10 Dynamic mechanical spectra of $(\bigcirc)$ PTFEPOH polymer and (O) base-catalyzed PTFEPOF/TEOS 50:50 composite. Reproduced with permission from reference 25. Copyright 1992, American Chemical Society.

Appl. Organometal. Chem. 13, 339-351 (1999) 
a Teflon ${ }^{\circledR}$ mold and cured at $110{ }^{\circ} \mathrm{C}$ to obtain freestanding films of the new composite material.

The resulting hybrids were characterized by DSC measurements, which revealed appreciable changes in the $T_{\mathrm{g}}\left(-59^{\circ} \mathrm{C}\right)$ and $\mathrm{T}(1)\left(50^{\circ} \mathrm{C}\right)$ values of the hybrid with respect to those of the original PTFEPOH homopolymer: by TGA experiments, which showed that the PTFEPOH/SiO ${ }_{2}$ composites have about the same thermal stability as the original fluorinated phosphazene substrate: and by DMTA analyses (Fig. 10), which gave the most interesting results. According to this Figure, the storage modulus of the phosphazene-based ceramics remains relatively high up to $140{ }^{\circ} \mathrm{C}$, where as the original PTFEPOH starts to flow already at about $50^{\circ} \mathrm{C}$, thus showing that the mechanical properties of the new hybrid are considerably improved with respect to those of the original polyphosphazene and remarkably extending the range of service temperatures of the fluorinated polymer to higher values. 25

As previously reported in the case of $\mathrm{MEEP} / \mathrm{SiO}_{2}$ composites, ${ }^{22,25,28}$ no chemical bond formation could be detected between the fluorinated phosphazene material and the three-dimensional silica network in these new composites.

\section{Poly[bis(4-hydroxyphenoxy $)_{0.8}(2,2,2-$

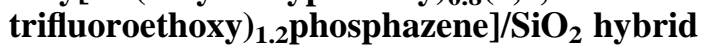 materials}

Our group faced the problem of forming a true chemical bond between the fluorinated phosphazene polymer PTFEPOH and the silica matrix in the composite material described above by taking a rather different point of view. It was thought that the highly flexible trifluoroethoxide units could be actually incorporated in the silica network to form the phosphazene-based hybrids, provided that it would be possible to insert these units in a phosphazene copolymer containing a free hydroxylic group, and then to react it with the silicon alkoxide precursor.

To achieve this aim we synthesized a new phosphazene copolymer, poly[bis(4-hydroxyphenoxy $)_{0.8}(2,2,2 \text {-trifluoroethoxy })_{1.2}$ phosphazene $],{ }^{36}$ by reaction of 4-methoxyphenoxy and 2,2,2-trifluoroethoxy anions (molar ratio 40:60) with polydichlorophosphazene, and successive deblocking of

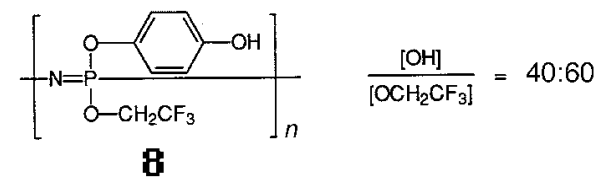

Copyright (C) 1999 John Wiley \& Sons, Ltd. the methoxide units with $\mathrm{BBr}_{3}$ to free the corresponding - $\mathrm{OH}$ groups. ${ }^{66}$ The final copolymer has the chemical structure $\mathbf{8}$.

In this substrate the presence of a high quantity of free hydroxylic groups allows the reaction of the PTFEP-POPOH phosphazene copolymer with hydrolyzed TEOS to form composites based on the fluorinated phosphazene substrates.

The resulting hybrids were prepared as transparent thick films (about $9 \mu \mathrm{m}$ ) with a $T_{\mathrm{g}}$ value of $26.4^{\circ} \mathrm{C}$ as determined by DSC. ${ }^{36}$

\section{Azo-POPOH/SiO 2 composites}

The general principle of the copolymerization reaction in phosphazene chemistry, ${ }^{86}$ as obtained by co-substituting two (or more) different nucleophiles on the same polydichlorophosphazene macromolecule, also proved to be very useful in the synthesis of new hybrid substrates that are highly colored in the visible range of the spectrum. ${ }^{31}$

These composites could be obtained by reacting freshly prepared poly[bis(4-hydroxyphenoxy)phosphazene] (vide infra) with diazotized aromatic amines, arbitrarily fixing the concentration of these species below the $20 \%$ of the free, phosphazenesupported, phenol groups.

The overall reaction sequence is shown in Scheme 1.

The reaction of these polymers with hydroxylated TEOS leads to the formation of new highy colored hybrid materials. Moreover, the color of the resulting films and its intensity are strictly correlated with both the type and the concentration of the azo derivatives supported on the phosphazene polymer.
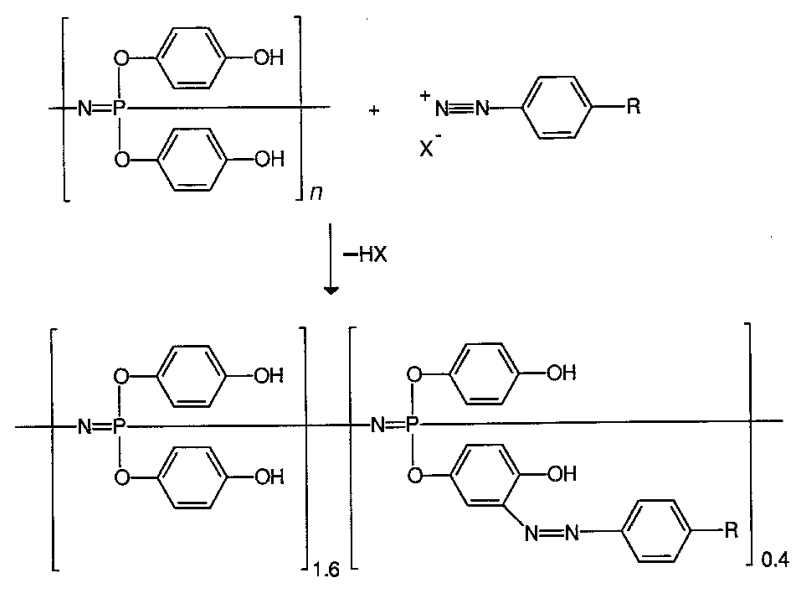

Scheme 1

Appl. Organometal. Chem. 13, 339-351 (1999) 


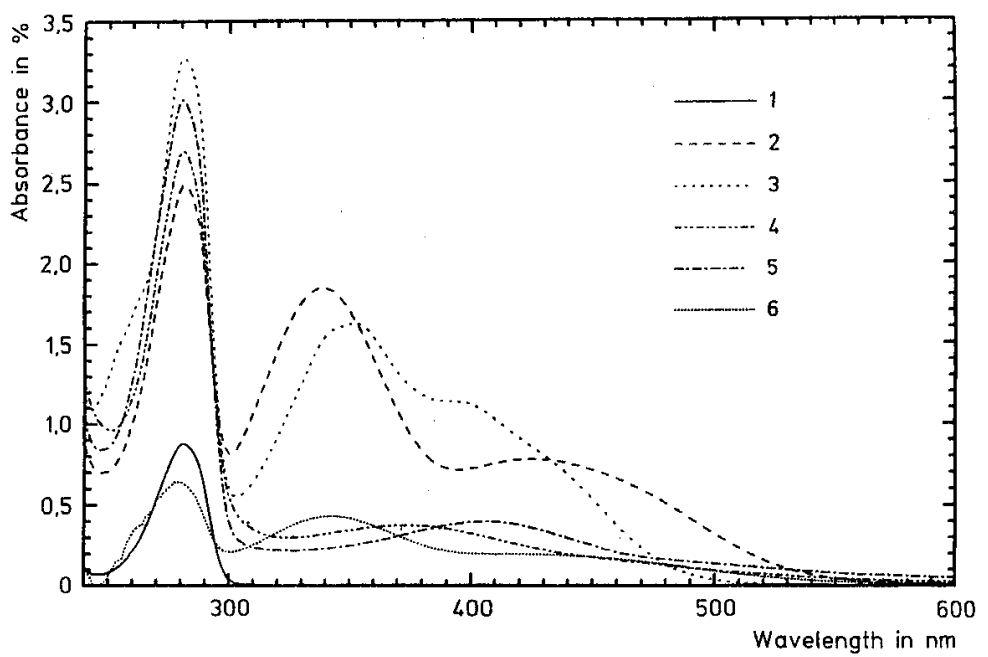

Figure 11 UV/Visible absorption spectra of: (1) POPOH; (2) POPOH containing $15 \mathrm{~mol} \%$ of azo dye formed with $p$-nitroaniline; (3) POPOH containing $5 \mathrm{~mol} \%$ of azo dye formed with $p$-methoxyaniline; (4) POPOH containing $20 \mathrm{~mol} \%$ of azo dye formed with 5amino-2-naphthalenesulfonic acid; (5)POPOH containing $15 \mathrm{~mol} \%$ of azo dye formed with $o$-aminophenol; (6) hybrid sol-gel films containing the colored polyphosphazene (1). (1)-(5) were all carried out in acetone solvent. Reproduced with permission from reference 31. Copyright Hüthig \& Wepf Verlag, 1995.

Examples of the spectral characterization of some new phosphazene-based ceramics are provided in Fig. 11.

\section{Poly[bis(phenoxy-4-sulfonic acid)phosphazene]/ $\mathrm{SiO}_{2}$ composites}

Allcock reported recently that new composites could be prepared by incorporating a water-soluble polyphosphazene (9) into silica networks. No additional information on this new phosphazene/ $\mathrm{SiO}_{2}$ composite is yet available.

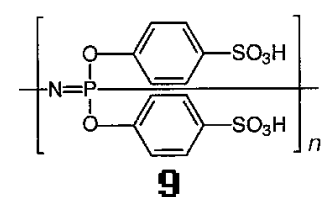

\section{CONCLUSIONS}

In this review the present status of research on both cyclo- and poly-phosphazene hybrid materials produced by the sol-gel technique has been highlighted.

Two main strategies have been explored up to now. In the first approach ${ }^{21,22,25,27,28}$ phosphazene polymers substituted with poly(ethyleneoxide) or trifluoroethoxide units were allowed to produce new composites with silicon, titanium, zirconium and aluminum oxides without any formation of chemical bonds between the components. In spite of this fact, however, a remarkable improvement in the mechanical properties of the polyphosphazene together with an extension of the range of service temperatures for the polymers, could be observed. In the second series of investigations, ${ }^{29-37}$ genuine covalent bonds in the polyphosphazene hybrid materials could be obtained by exploiting tailormade phosphazene macromolecules containing a high proportion of free hydroxylic functionalities.

In both cases the new hybrid materials containing phosphazene macromolecules were obtained as transparent bulk materials, flexible films or fibers, which could be characterized by thermal (DMTA, TGA, DSC, DTA), spectroscopic (SEM, EDAX, IR) and conductive (impedance) techniques.

Acknowledgements M. Guglielmi and M. Gleria are indebted to MURST and to the Progetto Finalizzato Chimica Fine e Secondaria II del Consiglio Nazionale delle Ricerche, respectively, for financial support.

\section{REFERENCES}

1. F. O. Stark, J. R. Falender, and A. P. Wright, Silicones. In: Comprehensive Organometallic Chemistry. The Synthesis,

Appl. Organometal. Chem. 13, 339-351 (1999) 
Reactions and Structures of Organometallic Compounds, Vol. 2, Wilkinson, G., Stone, F. G. A. and Abel, E. W. (eds), Pergamon Oxford, 1982, p. 305.

2. E. G. Rochow, Silicon and Silicones Springer-Verlag, Berlin, 1987.

3. S. Patai, and Z. Rappoport (eds), The Chemistry of Organic Silicon Compounds, John Wiley, New York, 1989.

4. H. R. Allcock, Heteroatom Ring Systems and Polymers, Academic Press, New York, 1967.

5. H. R. Allcock, Phosphorus-Nitrogen Compounds. Cyclic, Linear, and High Polymeric Systems Academic Press, New York, 1972.

6. J. E. Mark, H. R. Allcock, and R. West, Inorganic Polymers, Prentice Hall, Englewood Cliffs, NJ, 1992, Chapter 3, p. 61.

7. V. V. Kireev, G. S. Kolesnikov, and I. M. Raigorodskii, Russian Chem. Rev. 38, 667 (1969).

8. H. R. Allcock, and D. J. Brennan, J. Organometal. Chem 341, 231 (1988).

9. H. R. Allcock, and S. E. Kuharcik, J. Inorg. Organometal. Polym. 5, 307 (1995).

10. H. R. Allcock, and S. E. Kuharcik, J. Inorg. Organometal. Polym. 6, 1 (1996).

11. H. R. Allcock, and W. D. Coggio, Macromolecules 23, 1626 (1990).

12. H. R. Allcock, and W. D. Coggio, Macromolecules 26, 764 (1993).

13. H. R. Allcock, D. E. Smith, Y. B. Kim, and J. J. Fitzgerald, Macromolecules 27, 5206 (1994).

14. P. Wisian-Neilson, R. R. Ford, R. H. Neilson, and A. K. Roy, Macromolecules 7, 2089 (1986).

15. H. R. Allcock, and D. E. Smith, Chem. Mater 7, 1469 (1995).

16. R. L. Dieck, and E. J. Quinn, (assigned to Armstrong Cork Co.), US Patent 4026839 (1977): Chem. Abstr. 87, 24536b (1977).

17. P. Wisian-Neilson, and M. S. Islam, Macromolecules 22, 2026 (1989).

18. P. Wisian-Neilson, M. A. Schaefer, and M. S. Islam, ACS Polym. Prep. 30(1), 185 (1989).

19. P. Wisian-Neilson, M. S. Islam, and M. A. Schaefer, Phosphorus, Sulfur and Silicon 41, 145 (1989).

20. C. J. Binker, and G. W. Sherer, Sol-Gel Science, Academic Press, Boston, 1990.

21. C. J. T. Landry, W. T. Ferrar, and B. K. Coltrain, (assigned to Eastman Kodak Co.) PCT Int. Appl. WO 9109 080, (1991); Chem. Abstr. 115, 234535y (1991).

22. B. K. Coltrain, W. T. Ferrar, C. J. T. Landry, and T. R. Molaire, ACS Polym. Prep. 32(3), 477 (1991).

23. B. K. Coltrain, W. T. Ferrar, and C. J. T. Landry, assigned to Eastman Kodak Co. US Patent 5010128 (1991).

24. C. J. T. Landry, W. T. Ferrar, and B. K. Coltrain, (assigned to Eastman Kodak Co.) US Patent 5104602 (1992).

25. B. K. Coltrain, W. T. Ferrar, C. J. T. Landry, T. R. Molaire, and N. Zumbulyadis, Chem. Mater. 4, 358 (1992).

26. C. J. T. Landry, W. T. Ferrar, and B. K. Coltrain, (assigned to Eastman Kodak Co.) US Patent 5190819 (1993).

27. B. K. Coltrain, W. T. Ferrar, C. J. T. Landry, T. R. Molaire,

Copyright (C) 1999 John Wiley \& Sons, Ltd.
D. E. Schildkraut, and V. K. Smith, ACS Polym. Prep. 34(1), 266 (1993).

28. W. T. Ferrar, B. K. Coltrain, C. J. T. Landry, V. K. Long, T. R. Molaire, and D. E. Schildkraut, Polyphosphazene molecular composites. In: Inorganic and Organometallic Polymers II. Advanced Materials and Intermediates, Wisian-Neilson, P., Allcock, H. R. and Wynne, K. J. (eds), ACS Symp. Ser., No. 572, American Chemical Society, Washington, DC, USA, 1994, p. 258.

29. G. Facchin, G. Fantin, M. Gleria, M. Guglielmi, and F. Spizzo, ACS Polym. Prep. 34(1), 322 (1993).

30. M. Guglielmi, P. Colombo, G. Brusatin, G. Facchin, and M. Gleria, J. Sol-Gel Sci. Technol. 2, 109 (1994).

31. G. Facchin, M. Gleria, F. Minto, R. Bertani, M. Guglielmi, and G. Brusatin, Macromol. Rapid Commun. 16, 211 (1995).

32. M. Guglielmi, G. Brusatin, G. Facchin, and M. Gleria, $J$. Mater. Res. 11, 2029 (1996).

33. G. Brusatin, M. Guglielmi, R. De Jaeger, G. Facchin, M. Gleria, and M. Musiani, Sol-gel hybrid materials based on hydroxylated poly[bis(methoxy-ethoxy-ethoxy)phosphazene] and silica: a ceramic ionic conductor. In: Syntheses and Methodologies in Inorganic Chemistry. New Compounds and Materials, Vol. 6, Daolio, S., Tondello, E. and Vigato, P.A. (eds), Bressanone, 1996, p. 315.

34. M. Guglielmi, G. Brusatin, G. Facchin, M. Gleria, R. De Jaeger, and M. Musiani, Proc. 1st National Workshop on Cyclo- and Poly-Phosphazenes, Comm. C 14, Padua, Italy, 15-16 February 1996.

35. J. C. Pivin, G. Brusatin, M. Guglielmi, G. Facchin, and M. Gleria, Nucl. Instr. Meth. B. 112, 294 (1996).

36. M. Guglielmi, G. Brusatin, G. Facchin, M. Gleria, R. De Jaeger, and M. Musiani, J. Inorg. Organometal Polym. 6, 221 (1996).

37. G. Brusatin, M. Guglielmi, R. De Jaeger, G. Facchin, M. Gleria, and M. Musiani, J. Mater. Sci. 32, 4415 (1997).

38. J. C. Pivin, G. Brusatin, and G. Zalczer, Thin Solid Films 287, 65 (1996).

39. P. M. Blonsky, D. F. Shriver, P. E. Austin, and H. R. Allcock, J. Am. Chem. Soc. 106, 6854 (1984).

40. H. R. Allcock, and R. L. Kugel, J. Am. Chem. Soc. 87, 4216 (1965).

41. H. R. Allcock, R. L. Kugel, and K. J. Valan, Inorg. Chem. 5, 1709 (1966).

42. H. R. Allcock, and R. L. Kugel, Inorg. Chem. 5, 1716 (1966).

43. H. R. Allcock, Polym. Mater. Sci. Eng. 69, 98 (1993).

44. H. R. Allcock, Adv. Chem. Ser. 248, 1 (1996).

45. H. R. Allcock, R. J. Fitzpatrick, M. Gebura, and S. Kwon, ACS Polym. Prep. 28(1), 321 (1987).

46. H. R. Allcock, M. Gebura, S. Kwon, and T. X. Neenan, Biomaterials 9, 500 (1988).

47. L. Bonsignore, L. Corda, E. Maccioni, G. Podda, and M. Gleria, Gazz. Chim. Ital. 121, 341 (1991).

48. P. Zurer, Chem. Eng. News 62, 23 (1984).

49. H. R. Allcock, S. Kwon, G. H. Riding, R. J. Fitzpatrick, and J. L. Bennett, Biomaterials 9, 509 (1988).

50. H. R. Allcock, S. R. Pucher, and K. B. Visscher, Biomaterials 15, 502 (1994).

Appl. Organometal. Chem. 13, 339-351 (1999) 
51. D. F. Shriver, and G. C. Farrington, Chem. Eng. News 63 , 42 (1985).

52. M. A. Ratner, and D. F. Shriver, Chem. Rev. 88, 109 (1988).

53. M. Gleria, F. Minto, R. Bertani, and G. Facchin, Poly(organophosphazenes): synthesis, properties and applications. In: Syntheses and Methodologies in Inorganic Chemistry. New Compounds and Materials, Vol. 6, Daolio, S., Tondello, E. and Vigato, P. A. (eds), Bressanone, 1996, p. 195.

54. H. R. Allcock, P. E. Austin, T. X. Neenan, J. T. Sisko, P. M. Blonsky, and D. F. Shriver, Macromolecules 19, 1508 (1986).

55. H. R. Allcock, Polyphosphazenes a new biomedical and bioactive materials. In: Biodegradable Polymers as Drug Delivery Systems, Chasin, M. and Langer, R. (eds), Marcel Dekker, New York, 1990, p. 163.

56. G. Nazri, D. M. MacArthur, and J. F. Ogara, Chem. Mater. 1, 370 (1989).

57. H. R. Allcock, Macromolecular and materials design using polyphosphazenes. In: Inorganic and Organometallic Polymers II. Advanced Materials and Intermediates, Wisian-Neilson, P., Allcock, H. R. and Wynne, K. J. (eds), ACS Symp. Ser., No. 572, American Chemical Society, Washington, DC, USA, 1994, p. 208.

58. K. M. Tonge, and D. F. Shriver, J. Electrochem. Soc. 134, 269 (1987).

59. C. J. Nelson, W. D. Coggio, and H. R. Allcock, Chem. Mater. 3, 786 (1991)

60. J. L. Bennett, A. A. Dembek, H. R. Allcock, B. J. Heyen, and D. F. Shriver, Chem. Mater. 1, 14 (1989).

61. K. W. Semkow, and A. S. Sammells, J. Electrochem. Soc. 136, 767 (1987)

62. K. M. Abraham, M. Alagmir, and R. K. Reynolds, J. Electrochem. Soc. 136, 3576 (1989).

63. P. M. Blonsky, D. F. Shriver, P. E. Austin, and H. R. Allcock, Solid State Ionics 18/19, 258 (1986).

64. C. Delprato, R. De Jaeger, and D. Houalla, ACS Polym. Prep. 34(1), 320 (1993).

65. C. Delprato, R. De Jaeger, D. Houalla, and P. Potin, Macromolecules 28, 2500 (1995).

66. M. V. Bhatt, and S. U. Kulkarni, Synthesis 249 (1983).

67. A. Medici, G. Fantin, P. Pedrini, M. Gleria, and F. Minto, Macromolecules 25, 2569 (1992).

68. T. G. Tessier, J. M. J. Frechet, C. G. Willson, and H. Ito,
The photo-Fries rearrangement and its use in polymeric imaging systems. In: Materials for Microlithography, Thompson, L. F., Willson, C. G. and Frechet, J. M. J. (eds), ACS Symp. Ser., No. 266, American Chemical Society, Washington, DC, USA, 1984, p. 269.

69. G. Fantin, A. Medici, M. Fogagnolo, P. Pedrini, M. Gleria, R. Bertani, and G. Facchin, Eur. Polym. J. 29, 1571 (1993).

70. R. De Jaeger, and M. Gleria, Prog. Polym. Sci. 23, 179 (1998).

71. G. Fantin, M. Gleria, A. Medici, F. Minto, and M. Fogagnolo, Italian Patent MI 001464 (1993).

72. G. Fantin, M. Fogagnolo, A. Medici, P. Pedrini, F. Minto, and M. Gleria, Gdzz. Chim. Ital. 127, 287 (1997).

73. H. R. Allcock, and C. G. Cameron, Macromolecules 27, 3125 (1994)

74. H. R. Allcock, and C. G. Cameron, Macromolecules 27, 3131 (1994)

75. H. R. Allcock, Acc. Chem. Res. 12, 351 (1979).

76. P. E. Austin, G. H. Riding, and H. R. Allcock, Macromolecules 16, 719 (1983).

77. J. P. Chambrette, G. Pagniez, and P. Potin, French Patent 90 01689 (1990).

78. M. Gleria, Chem. Ind. (Milan) 70(11), (Supplement), 15 (1988).

79. I. C. Choy, and J. H. Magill, J. Polym. Sci., Polym. Chem. Ed. 19, 2495 (1981).

80. J. P. Critchley, G. J. Knight, and M. M. Wright, HeatResistant Polymers Plenum Press, New York, 1983, Chapter 8, p. 389.

81. G. Pezzin, G. Palma, S. Lora, and M. Carenza, Chem. Ind. (Milan) 73, 185 (1991).

82. A. H. DiEdwardo, F. Zitomer, D. Stuetz, R. E. Singler, and D. Macaione, Org. Coat. Prep. 36, 737 (1976).

83. G. S. Kyker, and T. A. Antkowiak, Rubber Chem. Technol. 47, 32 (1974).

84. C. W. R. Wade, S. Gourlay, R. Rice, A. Hegyeli, R. E. Singler, and J. White, Biocompatibility of eight poly(organophosphazenes). In: Organometallic polymers, Carraher, C. E., Sheats, J. E. and Pittman, C. U. (eds), Academic Press, New York, 1978, p. 289.

85. W. T. Ferrar, W. Lenhart, J. Lippert, T. Molaire, R. Guistina, and D. Brown, Phosphorus, Sulfur, and Silicon 41, 147 (1989).

86. S. H. Rose, J. Polym. Sci., Part B 6, 837 (1968). 